\title{
8 \\ Transparency, trust and public value
}

\author{
E. Allan Lind
}

My chapter concerns trust in government, a topic that has attracted considerable attention recently. I write from the perspective of an academic social psychologist, but one who has been involved in government and policy studies for many years. About 40 years ago, I began working for the US federal government - this was during the Carter administration; I worked for the research arm of the judicial branch-and as I look back, I am struck by how much better the technology of government is now than it was then. I am not thinking of electronic technology, but rather how much better we are now at using knowledge and research methods from the economic and social sciences to design and evaluate policy options.

Nowadays, we are often quite sophisticated in our research on the impact of policies and in our understanding of the social terrain that we are working with as we create and execute government initiatives. At the same time, though, there is a troubling trend with respect to at least one aspect of how well government works. Improvements in the science of government notwithstanding, people do not seem to think their governments work in their interest. Data compiled in recent years by the Organisation for Economic Co-operation and Development (OECD) show that, on average, public trust in government is decreasing. Figure 1 shows the percentage of poll respondents who said they trusted their national government. The graphs show the average trust ratings in 2007 
and 2012 for all of the countries included in the OECD data set, and they show the nation-specific percentages for Australia, New Zealand and the United States. The results general show a reduction in trust. New Zealand seems to have 'dodged the bullet' of erosion of public trust, but clearly in Australia and the United States something disturbing is happening.
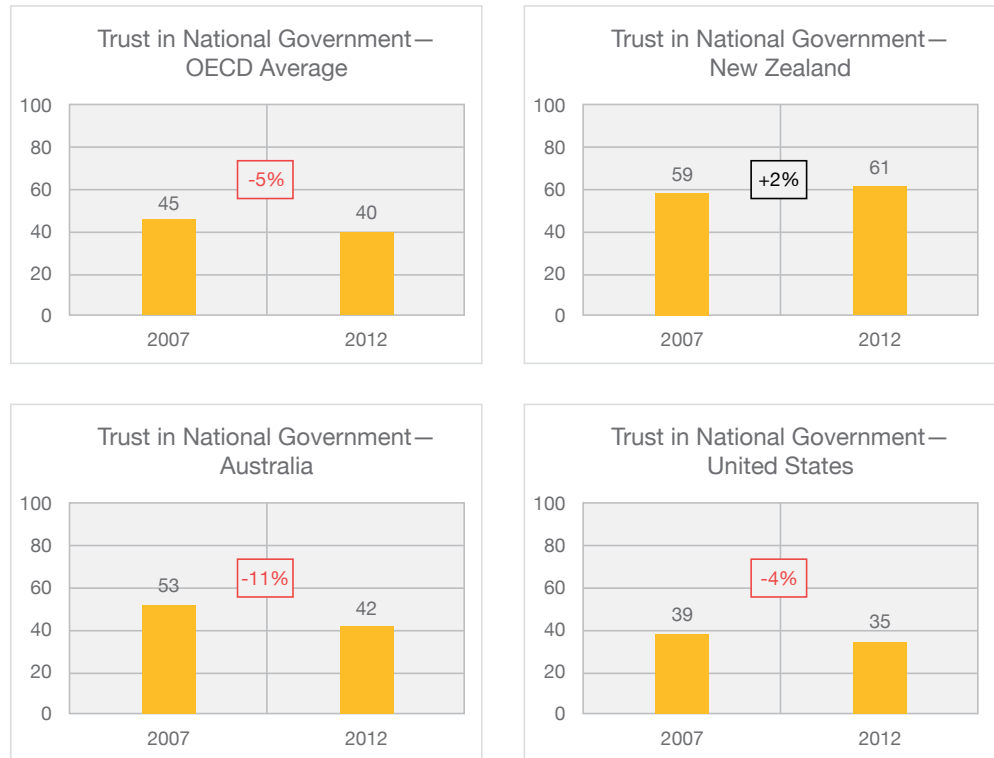

Figure 1: Percentage of poll respondents who trust their national government

Source: After OECD (2013).

The OECD data was collected across a five-year period, but the same trend is seen in longer-term comparisons, which show that in many countries, citizens' trust in government has been decreasing over the last several decades. This is a matter of concern for those of us who would like to think that government is an effective and valued realm of human endeavour. Disturbing, too, is the fact that it is trust in national government that is taking the biggest hit-Figure 2 shows the OECD trust averages for several societal institutions (in 2012). Trust in national government is lower than trust in the judicial system, local police, the education system and healthcare. (The data for the individual nations included in Figure 1 all show similar patterns of relative trust in these five 
institutions, again with the exception of New Zealand, where trust in the national government was slightly higher than trust in the judicial system, though lower than trust in the other three institutions.)

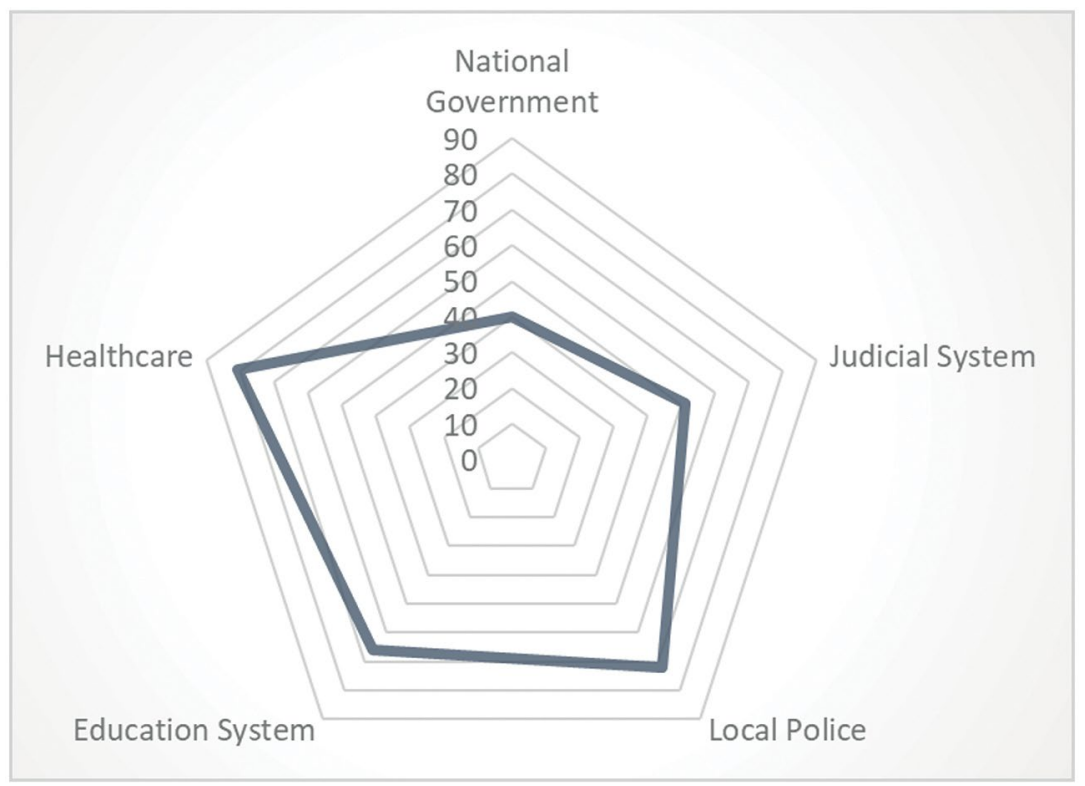

Figure 2: Trust in institutions

Source: After OECD (2013).

Why, if we are doing a better job of governing in some objective sense, is government seen as less trustworthy? Why do people not trust their national governments as much as they used to? As a psychologist, my major research interest is investigating this disconnect. My major research interest is to understand what exactly is happening with trust in government. Specifically, I study what is going on in citizens' experiences with government that might account for this erosion of trust.

A good place to start is to consider what the experience of government is like for most people. I will return to hard science later in this chapter, but I want to start framing the issue with two narratives about my own personal experiences with a private and a public organisation. The first experience-the private organisation experience-involved purchasing an iPad from an Apple Store. The other experience-the public organisation experience-involved taking my son to get a passport. His passport had expired and he was about to spend a university semester abroad studying 
in New Zealand. I think there are some interesting contrasts between these two experiences that illustrate some potential problem in how people experience their governments.

Let me start with the iPad experience. I decided I needed a new iPad, so I went to my local Apple Store: a bright, sunny building with lots of open space and large windows in the front. My first view of the store included all sorts of pictures and posters in the windows showing happy people enjoying the various electronic devices that could be purchased there. When you walk into an Apple Store-at least in Durham, North Carolina-you are immediately greeted by someone wearing an Apple T-shirt. The person who greets you is most likely a highly tattooed and much-pierced young person, but he or she is quite knowledgeable about Apple devices, as well as being highly trained in how to interact with you.

Apple Store employees are quite carefully taught skills such as how to greet potential customers. There is a well-designed and well-executed process that is used to pass a customer from the first salesperson encountered to the salesperson who specialises in the category of products that matches the customer's interest. When I entered the store, I was immediately approached and welcomed by a young man who introduced himself as 'Daniel'. Daniel welcomed me to the Apple Store and asked me how he could help me. When I told him I was interested in buying an iPad, Daniel told me 'Mark' was one of the store's iPad specialists. Daniel then explained that Mark was currently with another customer, but that if I would 'wait at this table'-where, incidentally, I could play with other Apple devices that I might also like to purchase-Mark would be with me shortly. Sure enough, in a few minutes Mark came over and talked to me about what I needed. He asked how I would be using my new iPad, explained the options available to me and advised me about what sort of services I might want. Mark made a point of mentioning, in an apparently a casual aside, that he was not paid on any commission, so I would know that he had no personal stake in my choice of product. He seemed to want me to find the iPad that was best for me. I walked out with an iPad and a memory of a positive experience with Apple. Now I am a business school professor-I know Apple does not really have an emotional need for me to like them. But they do-for business purposes- have a need to have a relationship with me, and they want me to feel good about my experience with their company. Judging by my personal experience, they execute that business strategy quite well. 
Now let us consider my second example. My son Pippin and I went to our local post office to get his passport. The Chapel Hill post office building is not as striking as the Apple Store, but it is a pleasant enough location. The post office, like the Apple Store, had an attractive sign inviting and informing us about the product we were seeking, this sign told us that passports were available here at the post office and it directed us to the door of the passport office. Unfortunately, when we arrived at the passport office things got a bit less inviting. We were confronted with a closed and locked door displaying a sign that read: 'Passport applications must be completed before the appointment time and in black ink only'. The word 'before' was written in red and underlined twice. Beneath that sign was another that read: 'By appointment only'. And beneath that was a third sign that said: 'Knock twice'. The implication was clear: if you do not have an appointment, we do not want to see you. If you have not already completed your passport application, we do want to see you. And, by the way, knock twice because we are not going to be paying much attention to your needs, so you had better make them very well known if you expect us to respond.

Fortunately, Pippin had made an appointment online, and he had already downloaded and completed his passport application. Good citizen that he is, he had even used black ink. He knocked twice, and after what seemed a long time, the door was opened by a postal service employee who was of a similar age to the Apple employees who helped me buy the iPad. Unlike the Apple folks, though, she was not particularly friendly. She checked Pippin's forms and executed her part of the applicationprocessing task competently, but she did so without a smile or any real personal engagement. The only remark she made that was even close to being individualised was an observation that Pippin's hair in the passport photo might be too long to be accepted by the State Department. The hair concern notwithstanding, in due time, Pippin got his new passport.

It occurred to me afterwards that these two experiences capture the essence of-and suggest a possible remedy for-some of the problems government has in building or maintaining public trust. For Pippin and me, the visit to the post office represented one of very few personal interactions we have with our national government. I pay my federal income taxes each year, but I do so without directly interacting with the government: my accountant prepares my tax forms and tells me how much to write the cheque for or, nowadays, gives the government permission to withdraw the amount due straight from my bank account. 
My personal, human experience with the US Government is limited to interactions like the one Pippin and I had at the post office. (I should note that in the US many routine government interactions-applying for or renewing a driver's licence, for example, are interaction with state, county or city governments.)

Now why did the US Department of State treat us this way? Why did they not show any of the interest in building a relationship that was so obvious at the Apple Store? I think the reason is that while Apple knows they want us to come back and buy more Apple devices and therefore they see the value in inviting us to maintain a relationship with Apple, the Department of State does not see itself as competing for our business. If you are an American, where else are you going to get a passport? The passport office is without competition, or at least most policymakers would think that to be the case.

I want to argue, though, that the Department of State is wrong about this. What many of the people who make policy and design government procedures do not seem to understand (or have not thought through) is that citizens, the 'consumers' of government, in fact do have another option. They can choose to withdraw their trust in and engagement with the government; they can 'leave' psychologically even though they remain in the country by deciding to give the government less of their personal support. In organisational scholarship, we have the concept of 'organisational withdrawal', a common response of employees who feel they are receiving unfair or inconsiderate treatment by their employer. An employee who feels mistreated might not be able to leave their job because they do not have other employment opportunities, but they can withdraw psychologically. These workers simply withdraw, spending less and less time actually working and showing less and less diligence in what work they do. Workers who withdraw psychologically work only when they have to and only when they are sure that they will be paid for each and every effort. Similarly, a citizen who has withdrawn psychologically from their relationship with their government will only obey laws when enforcement is certain and they will not 'take on faith' the truth of what the government tells them about the state of the world. In short, they will not trust their government.

I have to admit that, after our experience at the passport office, I felt a tug of this sort of negative feeling about the US Government. For myself, I did not give in to that 'tug' of resentment partly because many years ago 
I worked for the federal government and partly because I still have many friends who work in policymaking and policy research for governments around the world. From these experiences and acquaintances, I know that my government is staffed by hard-working, dedicated people. Therefore, I reminded myself that the way the local passport office was set upas an adjunct to the post office staffed by workers who were trained in postal, not passport, duties-was probably the result of an attempt to save money on passport services. I considered in addition that the absence of any real customer service training, which was evident in the behaviour of the young woman at the passport office, was due to the pervasive government preoccupation with squelching fraud and waste, with the result that she was probably trained only to make sure the forms were correct. In short, it seemed likely that our passport office experience was the result of a government that gives cost savings and fraud prevention very high priority and relationship building very low priority. Note that Apple, which has to make money, not just save money, to continue to exist, has discovered that giving too much attention to cost savings and too little attention to relationship building is not, in fact, good for their bottom line.

Now let me shift from these stories of personal experiences to science. Viewed from the perspective of several decades of work in social and political psychology, my different reactions to the Apple Store and the passport office are not at all surprising. Beginning in the early 1970s, these sciences began to see evidence that people experiencing encounters with government are affected by more than just the material rewards and costs associated with the encounter, that they react at least as strongly to how they feel they have been treated. Work by a number of scholars has shown that whether one studies litigant reactions to legal procedures or citizen reactions to lawmaking and law enforcement, the belief that one has been treated in a fair, straightforward and inclusive way has profound effects on later attitudes and behaviour. In the 1970s and 1980s, research I conducted with colleagues at the US Federal Judicial Center, at the University of Illinois, and at the RAND Corporation showed that litigants in civil cases were more willing to accept legal decisions and more likely to trust federal courts if they felt they had received fair, inclusive and dignified treatment.

At about the same time, research conducted by Tom Tyler and his students and colleagues at Northwestern University and the University of California at Berkeley showed that citizens accepted and obeyed laws 
more if they believed that the law-making process was fair and provided them with opportunities for voice and inclusion. In the years since those early studies, additional research, including some quite good studies done recently in Australia, has shown that in contexts ranging from traffic stops to interactions with tax offices to civil and criminal trials, citizen reactions to government are affected profoundly by the process and treatment the citizen experiences. I will elaborate more on these lines of research below, but first I would like to describe some very recent studies that show just how deeply embedded are concerns with inclusive and fair treatment. I should note before I begin describing this work that a great deal of work, going back to the studies I just mentioned, has shown that there is a very close psychological connection between feelings of fair treatment and feelings of inclusion and, in the negative, between feelings of unfair treatment and feelings of exclusion.

Let me describe some findings from the new and growing field of neurological studies of social behaviour. This research studies in detail how the human brain works. First, consider that the human brain is in fact the organ through which all government works. We can make laws and policies, but ultimately everything depends on people understanding, evaluating and deciding whether to comply. That said, let's consider how the brain works in guiding behaviour. We human beings have a section at the front of our brain that is quite remarkable among animal species. This 'forebrain' is where we do maths and where we resolve problems of logic. This part of the brain is what makes economics work, by weighing individual benefits and costs and deciding which actions are in one's selfinterest and which are not. But this is only part of the human brain, and it is only part of the story of how we make decisions and guide our behaviour. We humans also have another, important, portion of our brain, a part of the brain that evolved earlier but which is just as powerful. That part of the brain deals with social relationships.

The social part of the brain is preoccupied with how the person is being treated and what that treatment means for inclusion in important social groups and relationships. It plays a huge role in how we respond to people, groups and governments. There is some fascinating research on brain functioning that was published recently by Naomi Eisenberger, Matthew Lieberman and their colleagues and students at the University of California Los Angeles. In one set of studies, published in the journal Science. Eisenberger et al. (2003) recruited research participants and asked them to be the targets of functional magnetic resonance imaging 
(fMRI) while they were exposed to social experiences. fMRI machines are brain scanners that reveal what part of the brain is activated when the person being scanned is receiving a given stimulus experience. In this set of studies, the researchers exposed the participants to a computer game called Cyberball.

The game works like this: imagine you are lying in the fMRI machine, and you are asked to play a game of 'catch' on the computer screen in front of your face. The participants were told that there were two other participants (in other fMRI machines) who were playing the game with them. The game consists of catching the ball when it is thrown to you and then passing the ball to one of the other players. You operate a 'joystick' that controls a hand on a screen, and your movement of the joystick determines to whom you will throw the ball. (In fact, there was only the one participant-the behaviour of other two 'players' was in fact coded into the game software.) At first, the three players seemed to throw the ball to each other in a circular game of 'catch', with each player, including the real participant, catching the ball and then passing it on to the next person. After a while, though, the real participant found that the other two players began to pass the ball back and forth only to each other-the real participant was never again given the ball!

Eisenberger and her colleagues did this to see what the human brain does when the person is excluded-when he or she feels no longer 'part of the game'. What the researchers observed is that a specific part of the brain is activated when the participant is excluded-a brain area known as the anterior cingulate cortex. Once the participant was excluded from the game, more blood began flowing to that part of the brain. Now, what makes this finding remarkable and relevant to the topic under consideration here is that previous studies had shown that the anterior cingulate cortex is the part of the brain that is activated when participants are asked to stick their fingers into scalding water. This area is one of the brain's pain centres, a part of the brain that tells us we are hurt.

Eisenberger, Lieberman and their colleagues argue that this colocation of exclusion reactions and physical pain reactions makes sense because we have evolved as social animals and both exclusion and pain are important sensory cues. There was a time in our evolutionary history when being excluded from important groups meant one did not live very long. Consequently, early humans were more likely to survive if they developed a strong negative reaction to feeling excluded. As we evolved, 
the brain started using something it already had-the pain centre-to guide reactions to feelings of exclusion. Lieberman and Eisenberger point out that the comparisons that equate exclusion with pain are not just metaphors. Exclusion does not just feel like pain, the experience of exclusion is pain.

Other studies from this laboratory and other neuroscience labs show that just as feelings of inclusion activate a pain centre in the brain, the experience of fair treatment activates a pleasure centre. These neuroscience findings comport well with an older literature in social psychology, which had documented many instances where exclusion and unfair treatment makes people angry and combative while inclusion and fair treatment makes them cooperative and happier. Both lines of research suggest that if government can structure its interactions with citizens so that they feel included and fairly treated, it can provide direct and immediate benefits just by paying attention to how people are treated, simply by increasing inclusiveness and perceived fairness in the interaction.

With this immediate benefit of avoiding feelings of exclusion and promoting feelings of fair treatment in mind, we might ask a) how specifically government could promote such feelings, and b) what other positive consequences fair and inclusive procedures might have? A common argument in modern democracies is that citizens are de facto included in government decision-making and therefore treated fairly because they can vote on who makes and enforces the law. However, voting is a very indirect sort of inclusion, psychologically speaking. In the last US presidential election, for example, my vote represented approximately $1 / 136,000,000$ th of the decision-making control over the outcome-and that does not even consider the effects of the Electoral College system we have in the United States. In addition, knowing that one can vote is a forebrain, logical cognition: we understand, on a logical level, that if enough people like me vote in a particular way, we will change our government. Inclusion and fairness are more dependent on social brain than on forebrain processes; however, so knowing one can vote might not promote feeling that one is included in the body politic. The visit to the passport office I described earlier was a social brain kind of experience. The challenge in modern democracies is to find ways to build a greater feeling of inclusion and involvement with respect to national government. Voting is an important political right, but the research I just described, and that which I will describe below, suggests that we need to do more. 
Neuroscience studies show a biological basis for strong negative reactions to exclusion and strong positive reactions to fairness. The social psychological research yields the same conclusions. It is worth delving deeper into exactly how feelings of inclusion and feelings of fair treatment are linked. The connection is seen in an area that is called the psychology of 'procedural justice'. Some years ago, Tom Tyler and I sought to explain why exactly people often respond more strongly to the processes they experience than to the outcomes they receive (Lind and Tyler 1988). Our explanation, included in what we termed 'Group Value Theory', was that being treated fairly by those in authority or those who are the representatives of an important institution or organisation gives people a sign that they are included in the social bonds and boundaries of the social institution in question.

For this reason, we argued, as fair treatment increases the feeling of inclusion increases. Tyler and I proposed that feelings of inclusion in turn prompt a variety of other psychological reactions-people who feel fairly treated (and who therefore feel included) are more cooperative, they more readily accept the authorities in the institution and obey the decisions those authorities make, they are more likely to comply with the rules of the institution, and they have greater trust in the authorities and in the institution. On the other hand, people who feel unfairly treated (and therefore feel excluded) will be less cooperative, they will accept authorities and decisions less, they will be less likely to comply with rules, and they will trust the institution less. In the 30 years since Tom and I published our theory (and an extension of the theory called the 'Relational Model of Authority') (Lind and Tyler 1988), there have been many studies testing both the basic proposition that perceived fairness prompts feelings of inclusion and the additional propositions that, because of this connection with inclusion, feelings of fair treatment lead to greater compliance, obedience and trust. The results—some of which I will describe belowhave been right in line with what we theorised.

Figure 3 presents some recent data some colleagues and I collected on this often-observed pattern of connections between perceived fairness, inclusion and trust. In this study, we asked people whether they felt they had been treated fairly, whether they felt included in the system and its processes and decisions, and whether they trusted the authority with whom they had worked. As can be seen from the graphs, as perceptions of fair process increased so did feelings of inclusion, and as feelings of inclusion increased so did trust. 

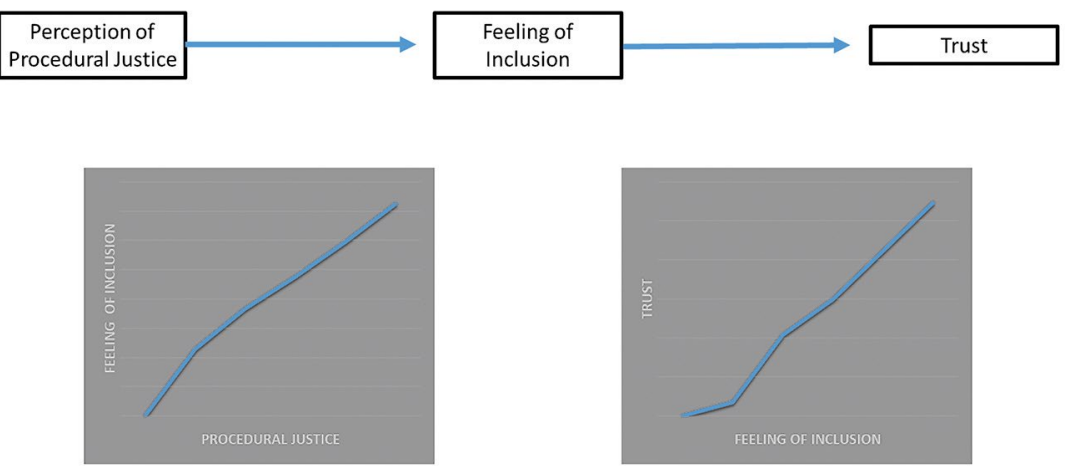

Figure 3: Perceptions of justice, inclusion and trust Source: Lind and Sitkin (2018).

If fair treatment fosters a feeling of inclusion and this builds trust in government, how might we increase feelings of fairness in citizengovernment interactions? Since much of the research documenting the link between fairness and trust has focused on procedural justice judgements, we would probably do best to look at how we might build feelings of procedural fairness. Let me note at the outset that procedural fairness judgements are not judgements about abstract fairness. They are judgements about how fairly one views some personal experience with government. These procedural fairness judgements tend to be influenced mainly by the rules and nuances of treatment encountered in an interaction with government, not so much by whether the ultimate outcome of the encounter was favourable or unfavourable. Procedural fairness judgements are also different to satisfaction. Immediate satisfaction with an interaction with government often has a stronger outcome component, but satisfaction reactions are also transient, and less enduring, than are procedural fairness judgements. Research in a variety of government contexts shows that satisfaction does not influence trust in government as much as procedural justice judgements do.

Four decades of research on procedural justice has identified some procedural and process elements that reliably increase the feeling that one has been treated fairly. This body of research shows four major features of an interaction with government that drive perceptions of fair treatment and, through fairness judgements, the feeling of inclusion. Three of these factors are especially relevant to interaction with government agencies in societies that are not prone to government corruption. In societies or nations where government processes, officials and decisions are open 
to corruption or bias, of course, the absence of such bias is also central, indeed often key, to whether the process is seen as fair. In most citizengovernment interactions in nations with fair degrees of transparency and without much corruption, the 'big three' fairness features are 'voice', respect and dignity, and explanations. 'Voice' refers to whether the individual is allowed to express his or her views, evidence and perspective, and whether the government authority shows evidence of considering these things. Respect and dignity as features of process refer to whether the authority treats the individual as a full person, with the respect for his or her decisions and with the dignity that everyone has a right to expect. The third feature-explanations-has to do with whether the authority or the government has explained in a comprehensible fashion how the process will unfold, how decisions will be made and why things are structured the way they are.

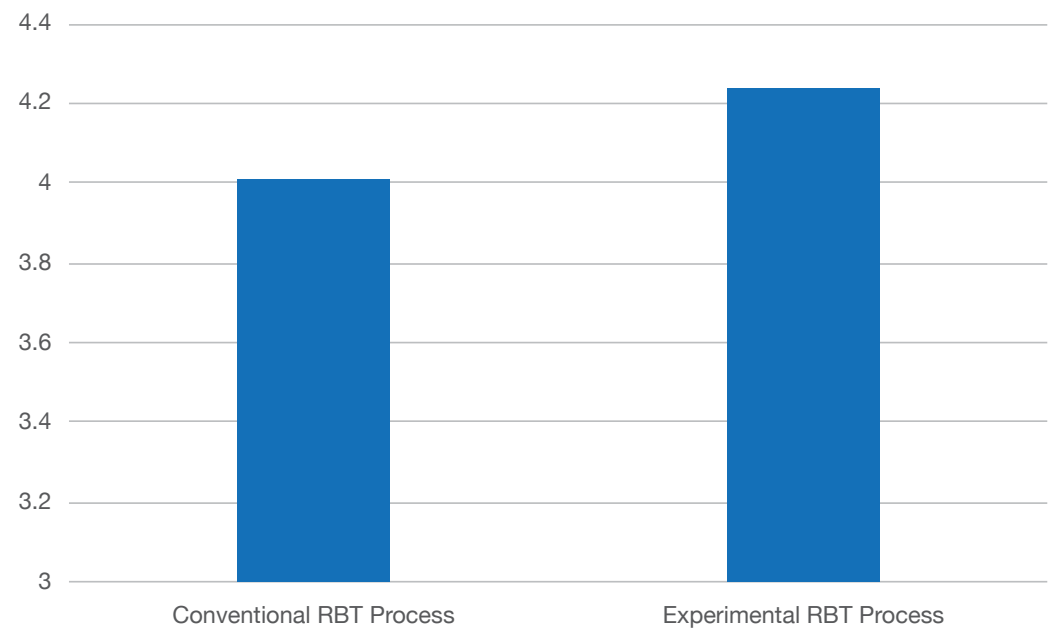

Figure 4: Perceived procedural fairness ratings

Note: RBT = Random Breath Testing

Source: After Mazerolle, Bennett, Antrobus and Eggins (2012).

Some recent research on alcohol breath-testing stops by police in Queensland, Australia, provides an excellent example of how governmentcitizen interactions can be modified to enhance citizen's perceptions of fair treatment. This research was conducted by Professor Lorraine Mazerolle of the University of Queensland and her colleagues, Sarah Bennett, Emma Antrobus and Elizabeth Eggins. In this Queensland Community Engagement Trial (QCET), the researchers, collaborating with the local 
police, created an experimental script to guide police actions when they made a random drink-driving stop. The police and the researchers were careful to include all of the 'big three' fairness elements in the experimental script for the traffic stop, and they compared drivers' reactions to this experimental script to reactions to the conventional process and actions used in these sorts of stops.

In the QCET experimental process - the fair process condition-when the police officer approached the driver's car, he or she explained to the motorist why they had been stopped. It was not the motorist's driving that prompted the stop, the officer explained, but rather simply because they had been randomly selected for breath testing. Thus, the process began with a clear explanation of the reason for the stop. The officer continued by explaining what would happen during and after the breath testing. While the officer was giving this explanation and throughout the interaction at the motorist's car, the experimental process dictated that the officer should squat down so that he or she would be looking eye-toeye with the seated motorist rather than looking down from a standing posture. These behavioural nuances and special attention to the use of polite language and demeanour by the officer were designed to convey a message of respect. Finally, as the stop progressed, the office asked the motorist to voice his or her opinion and views. Specifically, the officer asked what the driver being stopped thought should be done about drink driving.

Because the QCET study used a randomised research design, the researchers could make a strong and direct comparison between the fairness judgements engendered by the experimental process and the conventional process. Figure 4 shows the results-the experimental process produced more positive fairness experiences than did the conventional process. Here, in a real-world everyday government-citizen context, it was possible to make people feel more fairly treated just by modifying the process to incorporate voice, respect and explanations. It is not difficult to imagine how governments could make similar changes in process to enhance the experience of citizens across a wide variety of interactions with government agencies and offices.

Now let us consider what benefits might be realised if governments were to make these changes. Here, too, the research literature provides evidence of what might happen if the process and procedures of citizen-government interactions are such that they enhance feelings of fair treatment. First, 
improving perceived fairness would build trust in government and increase perceptions of the legitimacy of the government. I began this chapter with some data that show decreased trust in government across the OECD member nations in general, and in Australia and the US in particular. If we enhanced trust and legitimacy by increasing feelings of fair treatment on citizen interaction at the time, we might be able to reverse these disturbing trends

A study reported by Tom Tyler, Lawrence Sherman, Heather Strang, Geoffrey Barnes and Daniel Woods (2007) provides a nice example of how attention to fairness in the design of government procedures can enhance legitimacy and trust. This study, which was part of a restorative justice program in Canberra, examined the effects of a new procedure for dealing with habitual drink-driving cases, comparing the new procedure to the existing procedures used in such cases. The new process was designed to include the procedural justice elements of voice, respect and dignity, and explanations as well as other features that could help the offender become reintegrated into his or her family and community.

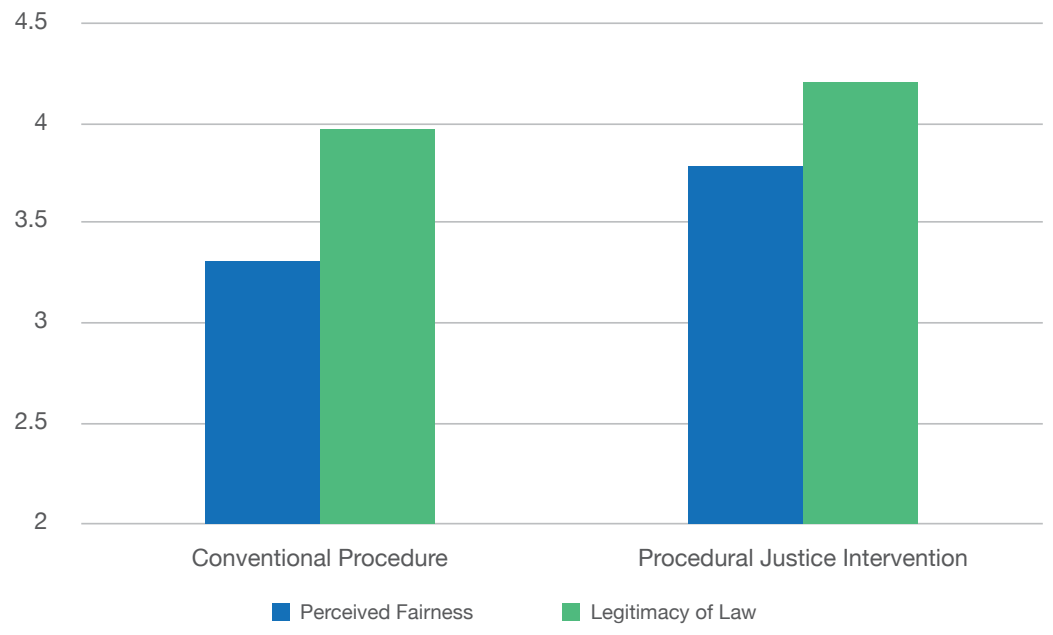

Figure 5: Perceived fairness and legitimacy in the Canberra RISE experiment

Source: After Tyler, Sherman, Strang, Barnes and Woods (2007).

Figure 5 shows the results of the RISE experiment. When the enhanced procedural fairness process was used, there was an increase in perceived fairness on the part of both the defendant and the defendant's families, and there was a corresponding increase in endorsements of the legitimacy 
of existing drunk-driving laws. This experiment demonstrates that it is possible to make people more trusting of government and more accepting of its legitimacy just by adding perceived fairness considerations into the design of process and procedures. Additional research by Tyler and other scholars have shown this strong connection between trust and legitimacy and perceptions of fair treatment in citizen-government interactions.

A second reason that governments would be well advised to design processes and procedures to enhance perceptions of fair treatment has to do with improving citizens' compliance with and acceptance of laws, rules and decisions. Early in my career, when I worked for the US Federal Judiciary and later for the RAND Corporation, I did a great deal of research on the question of what induces litigants to accept a judicial judgement rather than appeal the decision or simply not comply with it. Those studies, as well as research by other scholars, showed that acceptance of judicial and quasi-judicial decisions is strongly linked to the perception of fair process. Remarkably, the impact of procedural fairness judgements on acceptance of decisions is strong whether people win or lose their case. Even litigants who lose tend to accept and comply with the judge's or hearing officer's decision as long as they feel they were treated fairly in the legal process.

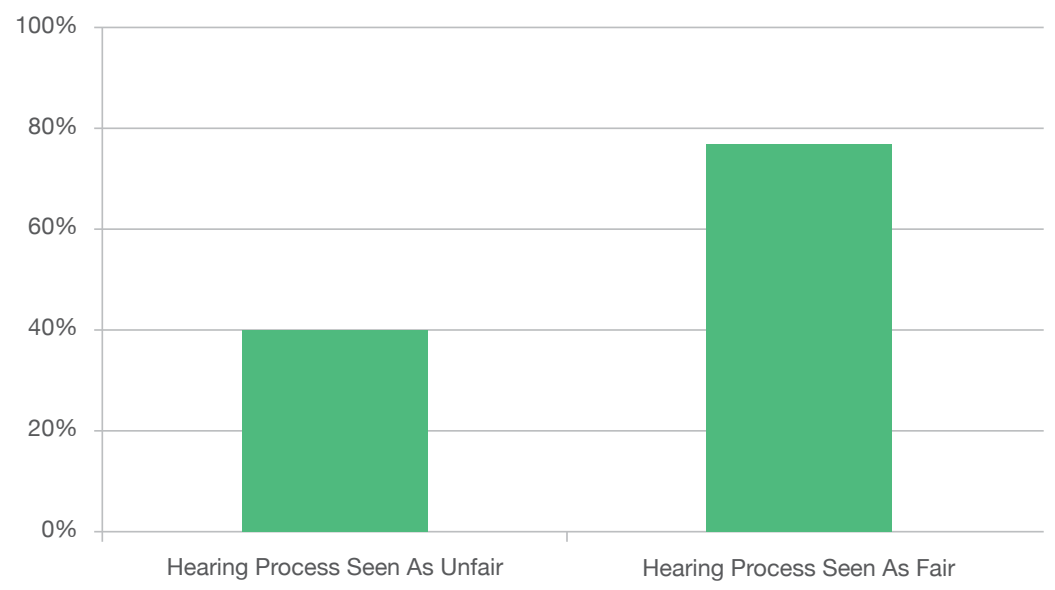

Figure 6: Perceptions of fairness in court-annexed arbitration procedures Source: After Lind, Kulik, Ambrose and Park (1993).

An example of this fairness effect can be seen in the research findings shown in Figure 6, which shows the results of studies on court-annexed arbitration procedures in the US federal courts. Carol Kulik, Maureen Ambrose, Maria de Vera Park and I studied what drove decisions to accept 
arbitrators' judgements in tort and contract cases subject to mandatory arbitration in federal district (trial) courts. We were interested in whether litigants' judgements of the fairness of the hearing process affected whether they would accept the arbitrators' judgements. (Under this version of arbitration, either party to a dispute could, at their discretion, reject the arbitration award and opt for a full trial.) The cases in question involved substantial amounts in controversy-up to several hundred thousand dollars. The findings were quite remarkable: even in these large disputes, feelings of fair treatment exerted strong influence on whether the arbitrator's judgement was accepted or appealed.

The link between perceptions of fair process and compliance was also seen in a recent study of pre-promulgation hearing procedures used to gather input for the design of government regulations. The regulation process studied in this research involved the creation of new rules governing pollutants in a major river system in my home state of North Carolina. The regulations under consideration would restrict how cities on the river could dispose of effluents and how farmers with fields along the river could fertilise crops. A series of public hearings were held to gather stakeholder and citizen input. My former student Kelly See studied how perceptions of the hearing process affected willingness to accept the regulations that the state government ultimately enacted. Figure 7 shows some of See's findings: hearing attendees who viewed the process as fair were more willing to accept the new regulations than were those who did not think the process was fair.

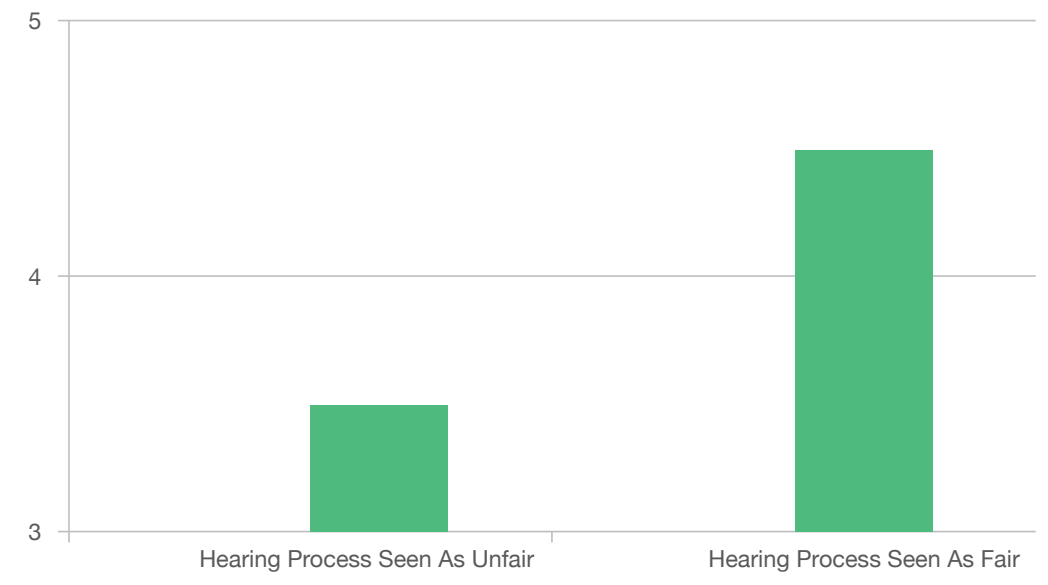

Figure 7: Perceptions of fairness and acceptance of regulations Source: After See (2009). 
I started this chapter with the assertion that many modern governments are doing the job of governing well, but they are not seen as doing their job well-at least they are not seen as trustworthy. I have reviewed the science on the social brain and the science on the psychology of perceived fairness because I think that at least part of the solution to the problem of growing distrust might be to pay more attention to improving citizens' personal experience with government. (I have only mentioned a few of the many relevant studies here, but interested readers can find more detailed descriptions and a useful bibliography in an OECD expert paper I authored with Christiane Arndt (Lind and Arndt 2016).) Research like that I have described here makes it clear that governments could increase citizen trust one interaction at a time, if they changed the procedures and processes used in citizen-facing policies and if they trained their staff to attend not only to administering laws and policies correctly but also to doing so in a respectful, clear and engaging manner.

\section{References}

Eisenberger, N.I., M.D. Lieberman and K.D. Williams. 2003. 'Does Rejection Hurt? An fMRI Study of Social Exclusion'. Science 302(5643): 290-92. doi.org/10.1126/science.1089134

Lind, E. and C. Arndt. 2016. 'Perceived Fairness and Regulatory Policy: A Behavioural Science Perspective on Government-Citizen Interactions'. OECD Regulatory Policy Working Papers, No. 6. Paris: OECD Publishing. doi.org/10.1787/1629d397-en

Lind, E., C.T. Kulik, M. Ambrose and M.V. de Vera. Park. 1993. 'Individual and Corporate Dispute Resolution: Using Procedural Fairness as a Decision Heuristic'. Administrative Science Quarterly 38(2): 224-51. doi.org/10.2307/2393412

Lind, E. and S. Sitkin. 2018. The Six Domains of Leadership. Columbia, SC: Learning with Leaders, p. 57.

Lind, E. and T.R. Tyler. 1988. The Social Psychology of Procedural Justice. New York: Plenum Press. 
Mazerolle, L., S. Bennett, E. Antrobus and E. Eggins. 2012. 'Procedural Justice, Routine Encounters and Citizen Perceptions of Police: Main Findings from the Queensland Community Engagement Trial (QCET)'. Journal of Experimental Criminology 8(4): 343-67. doi.org/ 10.1007/s11292-012-9160-1

Organisation for Economic Co-operation and Development (OECD). 2013. 'Government at a Glance 2013'. OECD: Paris. Available from www.oecd-ilibrary.org/governance/government-at-a-glance-2013/ confidence-in-national-government-in-2012-and-its-change-since2007_gov_glance-2013-graph1-en

See, K.E. 2009. 'Reactions to Decisions with Uncertain Consequences: Reliance on Perceived Fairness Versus Predicted Outcomes Depends on Knowledge'. Journal of Personality and Social Psychology 96(1): 104-18. doi.org/10.1037/a0013266

Tyler, T., L. Sherman, H. Strang, G. Barnes and D. Woods. 2007. 'Reintegrative Shaming, Procedural Justice, and Recidivism: The Engagement of Offenders' Psychological Mechanisms in the Canberra RISE Drinking-and-Driving Experiment'. Law \& Society Review 41(3): 553-86. doi.org.10.1111/j.1540-5893.2007.00314.x 
This text is taken from Opening Government: Transparency and Engagement in the Information Age, edited by John Wanna and Sam Vincent, published 2018 by ANU Press, The Australian National University, Canberra, Australia.

doi.org/10.22459/OG.04.2018.08 